\title{
GENERISANJE AKREDITACIONE DOKUMENTACIJE IZ ONTOLOGIJE STUDIJSKIH PROGRAMA
}

\section{GENERATION OF ACCREDITATION DOCUMENTATION FROM ONTOLOGY OF STUDY PROGRAMS}

\author{
Branko Ćorilić, Fakultet tehničkih nauka, Novi Sad
}

\begin{abstract}
Oblast - ELEKTROTEHNIKA I RAČUNARSTVO Kratak sadržaj - U ovom radu je opisana prototipska implementaciju aplikacije za generisanje dokumentacije za akreditaciju iz ontologije studijskih programa. Za opis studijskih programa korišćen je model meta podataka MLO ECTS IP/CC (ECTS Information Package/Course Catalogue MLO Application Profile). Kao mustra za generisanje dokumentacije korišćen je Word dokument kao i OpenXML (zipovan, XML baziran format razvijen od strane Microsoft-a).
\end{abstract}

Ključne reči: Akreditaciona dokumentacija, MLO ECTS IP/CC, ontologije, studijski program

\begin{abstract}
This paper describes a prototype implementation of an application for generating accreditation documentation from an ontology study program. The MLO ECTS IP / CC meta data model (ECTS Information Package / Course Catalog MLO Application Profile) was used to describe the study programs. As a template for documentation generation a Word document was used and OpenXML (zipped, XML based format developed by Microsoft )
\end{abstract}

Keywords: Accreditation documentation, MLO ECTS IP/CC, ontologies, study program

\section{UVOD}

Akreditacija visokoškolskih ustanova i studijskih programa visokog obrazovanja predstavlja proces u kome se formiraju uporedni međunarodni pokazatelji kojima se afirmiše kvalitetno obrazovanje. Po Bolonjskoj deklaraciji i Lisabonskoj konvenciji ona predstavlja jedan od preduslova za lakšu razmenu studenata i zapošljavanje diplomiranih stručnjaka. Sam proces izrade dokumentacije je prilično složen i podrazumeva zadovoljavanje određenih akreditacionih parametara potrebnih za akreditovanje studijskih programa i same visokoškolske ustanove. Neki od problema sa kojima se obrazovne institucije susreću pri procesu pripreme dokumentacije za akreditaciju su:

- preobilna dokumentacija (za različite standarde zahtevana je ista dokumentacija)

- promena parametara (promene u studijskom programu, promene nastavnog kadra) koje mogu da utiču i na više studijskih programa

\section{NAPOMENA:}

Ovaj rad proistekao je iz master rada čiji mentor je bio dr Milan Segedinac.
- kratak vremenski rok

Jedan od načina kako bi se ovi problemi mogli prevazići jeste predstavljanje dokumenata potrebnih za akreditaciju tehnologijama Semantičkog Veba (ontologijama) koje bi omogućile njihovo lakšu organizaciju, upravljanje po sadržaju, semantici i domenu, automatsko generisanje određenog dela dokumentacije.

Glavni motiv ovog rada jeste potreba da se proces kreiranja dokumentacije učini efikasnijim, bržim i manje sklonim greškama. Jedan od načina da se to učini jeste automatizacija procesa izrade dokumentacije gde bi se dokumentacija generisala programski, a izvor podataka bi bile popunjene ontologije koje predstavljaju akreditacionu dokumentaciju.

\section{TEORIJSKE OSNOVE}

\subsection{Ontologije}

Ontologije su deo W3C grupe standarda za Semantički Veb. Predstavljaju formalnu deljenu specifikaciju konceptualizacije [1]. To je formalni opis znanja kao skupa pojmova unutar nekog domena i odnosa koji postoje među njima.

\subsection{Office Open XML}

Office Open XML, takođe poznat kao OpenXML ili OOXML, je XML zasnovan format za Office dokument, uključujući dokumente za obradu teksta, proračunske tabele, prezentacije, kao i grafikone, dijagrame, oblike i drugi grafički materijal. Specifikaciju je razvio Microsoft, a ECMA International je usvojila kao ECMA-376 2006. Druga verzija je objavljena u decembru 2008., a treća verzija standarda objavljena u junu 2011. Specifikaciju su usvojili ISO i IEC kao ISO / IEC 29500.

\subsection{Bolonjski proces i proces akreditacije}

Bolonjski proces je masivni, višeslojni projekat sa ciljem formiranja evropske oblasti visokog obrazovanja (European Higher Education Area, EHEA) [2]. Bolonjskim procesom se želi postići veća koherentnost $\mathrm{u}$ visokoškolskim sistemima širom Evrope.

Ovim procesom je uspostavljen evropski prostor visokog obrazovanja kako bi se olakšala mobilnost studenata $\mathrm{i}$ osoblja, učinilo visoko obrazovanje inkluzivnijim i dostupnijim, a visoko obrazovanje u Evropi učinilo atraktivnijim i konkurentnijim širom sveta. 


\subsection{MLO-AD}

Metapodaci za obrazovna prilike (Metadata for Learning Opportunities -Advertising, MLO-AD) (CEN WS-LT, 2012) su model za predstavljanje meta podataka dovoljnih za opis i oglašavanje obrazovnih prilika. Model je dizajniran tako da bude prilagođen upotrebi semantičkih tehnologija i web arhitektura i da podrži različite mehanizme za razmenu i agregaciju informacija o obrazovnim prilikama. [3] Ovaj model je usvojen kao evropski standard CWA 15903:2008 (CEN WS-LT, 2008)

\subsection{MLO ECTS IP/CC}

ECTS informacioni paket/ katalog kurseva za MLO aplikacione profile (ECTS IP/CC) predstavlja proširenje MLO-AD definisano od strane evropskog komiteta za standardizaciju [4] kojim je definisan standard za predstavljanje kredita u skladu sa Evropskim sistemom prenosa i akumulacije kredita. Drugim rečima ovaj model predstavlja obrazac za opisivanje studija, nastavnih jedinica i visokoškolskih ustanova koje ih nude.

\section{ARHITEKTURA SISTEMA}

Arhitektura rešenja sastoji se iz sledećih sedam komponenti:

- Presentation Layer

- API Layer

- Access Control Layer

- Business Logic Layer

- Integration Service

- Persistence Layer

- Word (OpenXML) Processing Library

- File Storage Engine

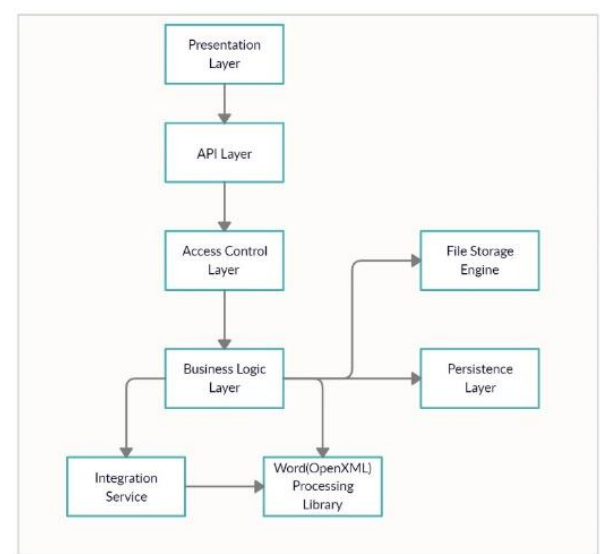

Slika 2.1 - Arhitektura prototipske implementacije aplikacije

3.1. Presentation Layer

Presentation Layer predstavlja korisnički interfejs koji omogućava korisniku upravljanje aplikacijom. Pomoću ovog sloja korisnik može da:

- unosi mustre u obliku Word dokumenta

- $\quad$ ima pregled unesenih mustri

- administrira mustre

- pretražuje mustre

- unosi/ menja markere koji služe kao placeholderi unutar mustre koji će se zameniti podacima iz ontologije prilikom generisanja dokumentacije

- Generiše dokumentaciju tako što će ručno popuniti unete mustre

- Generiše dokumentaciju automatski unosom ontologije studijskih programa

U ovoj aplikaciji korisnički interfejs predstavlja posebnu web aplikaciju koja je strukturno odvojena od ostatka aplikacije i komunicira sa Business Logic Layer-om REST pozivima koristeći HTTPS (Secure Hypertext Transfer Protocol).

\subsection{Access Control Layer}

Access Control predstavlja posebnu aplikaciju koja je zadužena za autentifikaciju i autorizaciju klijenata. Implementirana je kao posebni mikro servis u jeziku .Net Core. Podatke o klijentima (Tenant) čuva u odvojenoj MySQL bazi (tenantdb) kojoj samo ona ima pristup.

Komunikacija između Access Control aplikacije i Business Logic Layer-a omogućen je putem AccessControl klijentske biblioteke. Biblioteka je napisana tako da u potpunosti podržava DI prirodu .Net Core web aplikacija.

\subsection{API Layer}

API Layer predstavlja komponentu koja za cilj ima da omogući interakciju između korisničkog interfejsa i biznis logike aplikacije. Ona omogućava kreiranje RESTful servisa. Sastoji se iz vise controller klasa u kojima su definisani endpoints preko kojih je moguća komunikacija između korisničkog interfejsa i biznis logike. Implementirana je po DI parternu.

\subsection{Business Logic Layer}

Business Logic Layer je centralna komponenta koja povezuje sve druge komponente u sistemu. Njena uloga je da obavlja „biznis logiku“, tj. određuje set pravila koji upravljaju razmenom informacija između baze podataka (Persistance Layer) i korisničkog interfejsa (Presentation Layer), određuje logiku kako podaci su kreirani, čuvani ili promenjeni.

U ovoj aplikaciji biznis logika je implementirana u obliku servisa od kojih svaki od njih ima svoj interfejs što omogućava da ovakva arhitektura bude u potpunosti $u$ skladu sa DI paternom koji se koristi kroz aplikaciju.

\subsection{Persistence Layer}

Persistence Layer je komponenta koja služi za skladištenje podataka $\mathrm{u}$ aplikaciji (markera, podacima o mustrama). Ovoj komponenti podaci se prosleđuju preko Business Logic Layer-a i ona omogućava skladištenje podataka u MySql bazu podataka.

Cilj ove komponente je da omogući nezavisnu komunikacijo aplikacije sa bazom podataka od biznis logike aplikacije.

Prilikom implementacije ovog sloja nije korišćen ni jedan gotov Framework (npr. Entity Framework) za manipulaciju objektima sa MySql bazom već je dato svoje rešenje u obliku ručno pisane Entity Manager biblioteke. 


\subsection{Word (OpenXML) Processing Library}

Word (OpenXML) Processing Library-a je biblioteka koja manipuliše Word dokumentima koristeći OpenXML. U ovoj aplikaciji uloga ove biblioteke je višestruka:

- Služi za generisanje grafičke reprezentacije mustre koje je korisnik uneo preko korisničkog interfejsa uplodovanjem Word dokumenta; Prilikom uplodovanja Word dokument koji je u osnovi XML mapira se u odgovarajući HTML

- Služi za zamenu markera unutar mustre sa odgovarajućim podacima dobijenih od integracionog sloja

Omogućava automatsko ekstrahovanje markera iz Word dokumenta koji predstavlja mustru

\subsection{File Storage Engine}

File Storage Engine (FSE) predstavlja posebnu aplikaciju koja služi upravljanje i čuvanje dokumenta. Osnovna ideja File Storage Engine-a je da se dokumenti čuvaju na hard disku kompjutera unutar direktorijuma i pod direktorijuma a meta podaci o dokumentima unutar relacione MySQL baze.

\section{VERIFIKACIJA}

U ovom poglavlju opisana je prototipska implementacija aplikacije za generisanje dokumentacije za akreditaciju iz ontologije studijskih programa. Ova implementacija je opisana kroz praćenje procesa neophodnih za uspešan završetak zadatka, tako da je ovo poglavlje podeljeno na 3 dela:

- Administracija markera

- Administracija mustri

- Generisanje dokumentacije iz ontologije

\subsection{Administracija markera}

U ovoj aplikaciji markeri predstavljaju označavajuće reči koji se umeću unutar Word dokumenta. Njihova uloga je dvojaka. Prilikom generisanja korisničkog interfejsa oni se generišu u polja za unos podataka a prilikom generisanja dokumentacije oni služe kao objekti na koje se mapiraju odgovarajući podaci iz ontologije.

Postoje 2 tipa markera, prosti koji predstavljaju 1 objekat i složeni koji služe za predstavljanje lista objekata.

Da bi prosti marker bio dobro formiran unutar Word dokumenta on mora da počinje sa $\{\{$ i završava se sa $\}\}$ zagradama.

Složeni markeri predstavljaju listu objekata koja treba da se zameni prilikom generisanja dokumentacije. U osnovi ovaj marker je zamišljen kao trodimenzionalni niz veličine [1][n][m] gde prva dimenzija predstavlja identifikator tipa objekta, druga prestavlja atribute objekta a treća listu vrednosti atributa. U Word dokumentu ovi markeri mogu imati primenu prilikom generisanja složenih struktura kao što su tabele ili liste gde je za generisanje, kao izvor podataka, potrebno proslediti niz složenih objekata gde svaki objekat predstavlja jedan red. Slika 2.2 prikazuje primer korišćenja složenog markera.

\begin{tabular}{|c|c|c|c|c|}
\hline \multicolumn{5}{|c|}{ Литература } \\
\hline P. $.5 \mathrm{p}$. & Aytop & Назив & Издавач & Година \\
\hline $\begin{array}{l}\text { Siliterat } \\
\text { uraykr } \\
\text { bri] }\end{array}$ & S\{literatura\}autor\} & sqliteratura\}\{naziv\}? & S\{ilieratura\};[zdavac\} & $\begin{array}{l}\text { Spliteratu } \\
\text { rafygodin } \\
\text { a) }\end{array}$ \\
\hline
\end{tabular}

Slika 2.2 - Prikaz korišćenja složenog markera

\subsubsection{Ručni unos markera}

Markeri mogu ručno da se kreiraju i ažuriraju preko forme za ručno ažuriranje. Razlog zbog čega je data mogućnost da se ručno unose markeri je zbog toga što se ti markeri pretvaraju prilikom generisanja UI prikaza obrasca u polja za unos podataka koji imaju placeholder atribut koji je moguće koristiti za opis polja.

\subsubsection{Automatski unos markera}

Pored ručnog unosa moguće je da se markeri kreiraju automatski prilikom procesa kreiranja mustre za generisanje dokumentacije.Markeri se unutar Word dokumenta, koji predstavlja novu mustru, označavaju po principu \{\{ime_markera $\}\}$. Kada se Word dokument unese putem forme za unos Word (OpenXML) Processing Library očitava dokument i pretražuje sve markere unutar njega. Zatim proverava se da li su ti markeri već sačuvani u MySQL bazu. Ako nisu onda se kreira novi marker gde je ime markera vrednost između $\{\{$ i $\}\}$ zagrade.

\subsection{Administracija mustri}

Pre početka generisanja same dokumentacije za akreditaciju iz ontologije studijskih programa pored kreiranja markera potrebno je i uneti Word dokumenta sa markerima koji će predstavljati mustru za generisanje.

\subsubsection{Unos mustre za generisanje dokumentacije}

Prvi korak u procesu kreiranja nove mustre za generisanje dokumentacije jeste da korisnik definiše Word dokument koji prestavljati mustru za generisanje. U tom Word dokumentu potrebno je da sam ručno doda markere koje treba da zamene podaci iz ontologije pri automatskom generisanju. (pored ontologije izvor podataka može biti i Excel dokument). Pri korišćenju markera treba da se pazi da razmaci između $\{\{$ i $\}\}$ se ne ignorišu i da su markeri case sensitive. Slika 2.3 prikazuje primer Word dokumenta koji je služio kao mustra za generisanje dokumentacije.

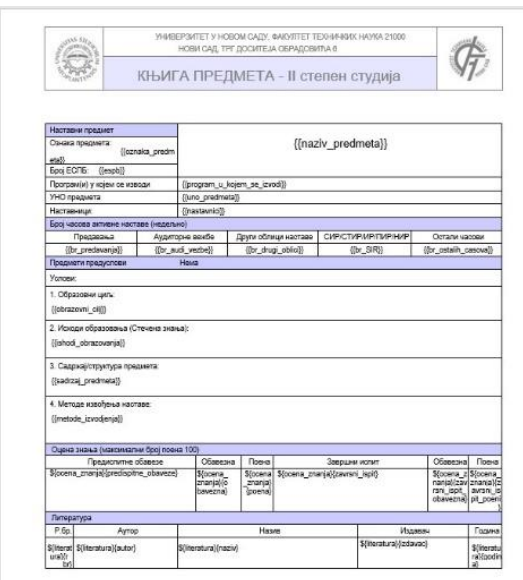

Slika 2.3 - Prikaz Word dokumenta sa popunjenim markerima za mustru

Nova mustra se unosi preko forme za ažuriranje mustri. Uplodovani dokument se prvo šalje File Storage Engine-a koji ga sačuva i vraća ID originalnog sačuvanog dokumenta.

Zatim dokument se skenira pomoću Word (OpenXML) Processing biblioteke koja dokument parsira kao jedan XML objekat (pomoću OpenXML). Iz tog objekta izvlače se svi markeri, proveravaju da li su sačuvani u bazi podataka, kreiraju novi koji već nisu sačuvani. Zatim se 
XML reprezentacija Word dokumenta konvertuje u HTML dokument a pri tom se pazi da vizualni prikaz Word dokumenta ostane isti i da atributi i elementi iz XML objekta mapiraju na odgovarajuće elemente i atribute u HTML-u.

Sledeći korak je zamena markera odgovarajućim poljima za unos. Name atribut markera mapira se na $n$ g-model atribut a HTMLPlaceholderValue na atribut placeholder. Ovakvo mapiranje omogućava da polja za unos kreirana od istih markera uvek bude isto popunjena.

Kao Http Response vraća se objekat koji sadrži ID originalnog sačuvanog dokumenta i HTML koji vizualno predstavlja unetu mustru u aplikaciji.

Na korisničkom interfejsu HTML koji je izgenerisan se prikazuje korisniku. To je moguće zbog AngularJS \$sce (Strict Contextual Escaping) servisa i njegove metode trustAsHtml(vrednost) koja omogućava generisanje HTML-a.

Da bi mustra mogla da se koristi dalje u procesu generisanja dokumentacije potrebni je uneti njen naziv $i$ na kraju pritisnuti dugme sačuvaj.

\subsection{Generisanje dokumentacije iz ontologije}

Generisanje dokumentacije se vrši tako što se prvo sa forme obrasci izabere odgovarajuća mustra na osnovu koje će se vršiti generisanje. Prilikom odabira mustre otvara se forma za generisanje. Na toj formi postoje dva načina da se generiše dokumentacija:

1. Ručno popunjavanjem polja za unos na mustri

2. Automatski tako što će se uneti popunjena ontologija kao izvor podataka

\subsubsection{Integracioni sloj}

U slučaju da korisnik odluči da generiše dokumentaciju automatski potrebno je da uploduje odgovarajuću ontologiju iz koje će se izvući podaci potrebni za generisanje. U ovom zadatku za potrebe generisanja dela akreditacione dokumentacije korišćena je ECTS IP/CC ontologija koja predstavlja studijske programe.

Ontologija je popunjena konkretnim podacima $\mathrm{i}$ oni su $\mathrm{u}$ ontologiji predstavljeni kao Individuals. Za vađenje podataka iz ontologije korišćena je gotova open source biblioteka OwlDotNetApi koja predstavlja RDF driven parser za C\# .NET i u potpunosti je u skladu sa W3C OWL sintaksom.

Mapiranje izvučenih podataka iz ontologije na strukturu koja odgovara markerima u mustri je u ovoj prototipskoj aplikaciji obavljeno ručno, međutim autor predlaže da se u budućnosti aplikacija proširi i da se omogući korisniku mogućnost da preko posebne forme mapira objekte iz učitane ontologije na odgovarajuće markere i na taj način podaci mapiraju automatski na potrebnu strukturu.

\subsubsection{Manipulacija originalnog dokumenta i} generisanje

Kada se podaci izvuku iz ontologije i mapiraju na strukturu koja je potrebna za generisanje pomoću File Storage Engine-a se vraća originalni dokument sa hard diska. Pravi se kopija dokumenta i ona se otvara uz pomoć Word (OpenXML) Processing Library biblioteke. Zatim se uz pomoć metode: pronađu svi markeri u dokumentu i zamene sa podacima iz ontologije. Ako su podaci iz ontologije struktuirani tako da prestavljaju listu objekata (npr. listu studijskih programa) generiše se onoliko Word dokumenata koliko ima objekata u listi. Na kraju se svi ti Word dokumenti spoje u jedan i kao takav vrate korisniku koji taj novo kreirani Word dokument skine na svoj kompjuter. Time je gotov proces automatskog generisanja opisan $\mathrm{u}$ ovom radu.

\section{ZAKLJUČAK}

U okviru ovog rada predstavljena je prototipska implementacija aplikacije koja olakšava kreiranje dela dokumentacije za akreditaciju. Ova aplikacija automatizuje proces generisanja dokumentacije potrebne za akreditaciju studijskih programa iz ontologije koja predstavlja podatke o studijskim programu.

Za opis studijskih programa korišćen je model meta podataka MLO ECTS IP/CC (ECTS Information Package/ Course Catalogue MLO Application Profile). Kao mustra za generisanje korišćen je Word dokument u kome se nalaze označavajuće reči (markeri) koje označavaju mesto gde treba da se mapiraju podaci. Open XML jezik korišćen je za manipulaciju originalnog Word dokumenta, kao i mapiranje podataka neophodnih za generisanje iz ontologije na mustru.

Ovim rešenjem postignuta je osnova za brzo automatsko generisanje dokumentacije za akreditaciju.

Mapiranje izvučenih podataka iz ontologije na strukturu koja odgovara markerima u mustri je u ovoj prototipskoj aplikaciji obavljeno ručno.

Budući rad na ovoj aplikaciji bi trebao da bude usmeren ka tome da se omogući generisanje i drugih delova dokumentacije potrebnih za akreditaciju. Jedan od načina kako bi se to moglo postići je omogućavanje korisniku da sam dinamički, preko aplikacije, mapira unesene ontologije sa markerima u unetim mustrama. Na taj način bi se omogućilo generisanje bilo koje dokumentacije iz odgovarajuće ontologije.

\section{LITERATURA}

[1] Antoniou, Grigoris, and Frank Van Harmelen. $A$ semantic web primer. MIT press, 2004.

[2] Terry, Laurel S. "The Bologna Process and its Impact in Europe: it's so much more than degree changes." Vand. J. Transnat'l L. 41 (2008): 107.

[3] Milan Segedinac, Razvoj proširive softverske platforme za upravljanje kurikulumom $u$ internacionalizovanom visokom obrazovanju, doktorska disertacija, 2014

[4]WS-LT, CEN. "ECTS Information Package." Course Catalogue MLO Application Profile (2010).

\section{Kratka biografija:}

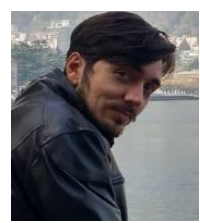

Branko Ćorilić rođen je u Novom Sadu 1989. god. Master rad na Fakultetu tehničkih nauka iz oblasti Primenjene računarske nauke i informatika odbranio je 2019.god. kontakt: corilic@gmail.com 